\title{
CIÊNCIA DA INFORMAÇÃO ENQUANTO CAMPO DE POTÊNCIA INTERDISCIPLINAR
}

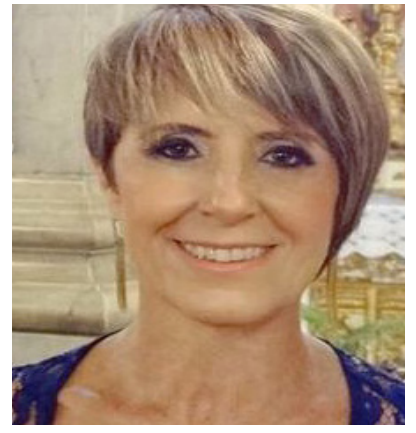

\section{Entrevista com a} Profa. Dra. Henriette Ferreira Gomes
Doutora e Mestre em Educação pela Universidade Federal da Bahia e Bacharel em Biblioteconomia e Documentação pela Fundação Escola de Sociologia e Política de São Paulo. Professora Titular do Instituto de Ciência da Informação da Universidade Federal da Bahia. Vice-Diretora do Instituto de Ciência da Informação da Universidade Federal da Bahia. Docente permanente do Programa de Pós-Graduação em Ciência da Informação do Instituto de Ciência da Informação da Universidade Federal da Bahia. Presidente da Associação Nacional de Pesquisa e Pós-Graduação em Ciência da Informação - Biênio 2016-2018. Líder do Grupo de Pesquisa CNPq Estudos e Pesquisa em Mediação e Comunicação da Informação. Áreas de atuação: Mediação da Informação; Relações entre Informação, Comunicação e Educação; Fundamentos históricos e epistemológicos em Ciência da Informação e Biblioteconomia; Organização da Informação; Documentação científica; Metodologia da Pesquisa Científica. E-mail: henriettefgomes@gmail.com.
I\&S - Recentemente, você está trabalhando com o conceito de protagonismo social no campo da Biblioteconomia. Fale sobre essa abordagem do profissional bibliotecário na sociedade contemporânea.

HFG - Inicialmente gostaria de agradecer a oportunidade de falar aos leitores do periódico Informação \& Sociedade. E manifestando a minha resposta, pontuaria que venho discutindo sobre as relações entre Informação e o Protagonismo Social, o que coloca nossa discussão no espectro de todo conjunto das reflexões e também atuações profissionais em torno do objeto Informação, entre os quais se inclui o profissional bibliotecário.
Ao tratar do protagonismo social, tomo como referência a abordagem de protagonismo cultural do Prof. Edmir Perrotti. O mesmo nos alerta que "[...] protagonismo implica uma dimensão existencial inextricável. Significa resistência, combate, enfrentamento de antagonismos produzidos pelo mundo físico e/ ou social e que afeta a todos. Significa tomada de posição dianteira face aos obstáculos que ameaçam a espécie (causados por pessoas, animais, circunstâncias, sentimentos, ideias, preconceitos etc.). Daí que protagonistas assumem a luta pela construção, pela criação, como atitude face ao mundo. Lutar, mais que enfrentamento 'contra', é modo de ser e de estar, 
de produzir e cuidar de um mundo comum, habitável e convivial" (PERROTTI, 2017). Neste sentido, o protagonismo é social, tratase de uma conduta, uma postura, um modo de existência que envolve todas as esferas da vida humana, nas suas diversas dimensões, incluindo a dimensão cultural, compreendendo-se cultura como produção humana, na qual se inclui o objeto informação.

Assim, quando trabalho com o conceito de protagonismo, o faço buscando focalizar de modo mais central as relações entre informação e o protagonismo social, ousando alcançar um delineamento que contorne e assinale a responsabilidade social do conjunto de profissionais que trabalha com o objeto informação, entre os quais está situado o profissional bibliotecário. Em verdade, nossos estudos e reflexões colocam em pauta uma discussão que ressalta a importância de avançarmos na realização da mediação consciente da informação, tomando como referência o conceito de mediação da informação de Oswaldo Almeida Junior. Assim, fechando a questão colocada, eu destacaria que as discussões que temos traçado acerca das relações entre informação e protagonismo se colocam na direção de argumentar acerca da importância de uma consciência dos profissionais da informação, entre os quais o bibliotecário, de que seu fazer e sua disciplina científica têm na mediação da informação uma centralidade sólida, que precisa ser assumida com a consciência e coragem próprias de um protagonista social, portanto, comprometido em proporcionar aos seus usuários as condições para a apropriação da informação, que poderá sustentar atitudes e ações protagonistas destes nas esferas da vida privada e social, protagonizando, enfim, as mudanças na sociedade.

I\&S - A Ciência da Informação se define como um campo científico interdisciplinar. Como seu Doutorado foi em Educação, quais os pontos que considera convergentes e com possibilidades de interseção entre Ciência da Informação e Educação?

HFG - Aqui eu faço um destaque que considero importante. Sempre analiso essas questões partindo das contribuições de Olga Pombo em torno da interdisciplinaridade e da transdisciplinaridade, o que me permite assumir uma postura mais cética quanto a tal assertiva frequente na literatura da área. $\mathrm{Na}$ minha concepção a Ciência da Informação não é, por natureza, interdisciplinar. Compreendo a Ciência da Informação como um campo científico que tem uma potência interdisciplinar, exatamente por ter como objeto central de estudo a informação. Seu fenômeno de estudo é complexo e demanda uma diversidade de "olhares" e de perspectivas que possibilitem as sucessivas aproximações com a realidade, da qual emerge a informação e na qual esta é organizada, acessada e apropriada pelos sujeitos sociais. Nessa perspectiva, podemos dizer que a Educação, ao tratar do processo de construção do conhecimento e das práticas de ensino-aprendizagem, se situa em uma fronteira de diálogo interdisciplinar com a Ciência da Informação, ainda que ambas careçam da força e atitude condutora e indutora de projetos e programas dialógicos. No entanto, há uma potência a ser trabalhada pelos dois campos.

Tomando por base o meu próprio conceito de informação como conhecimento em estado de compartilhamento (GOMES, 2016, 2017), entendo que a Ciência da Informação, ao jogar luz sobre o processo de geração da informação, assim como sobre a mediação que potencializa o processo de recepção e apropriação da informação, se aproxima dessa fronteira interdisciplinar com a Educação. Isso nos coloca frente ao desafio da conquista do diálogo interdisciplinar, capaz de formular projetos e programas de pesquisas que coloquem essas áreas mais próximas da construção de uma efetiva interdisciplinaridade. Aqui, então, construção é a palavra-chave que nos convida a assumir o comportamento cético quanto às assertivas sobre a "natureza interdisciplinar" da Ciência da Informação. Em realidade, a interdisciplinaridade é essencialmente uma construção e não uma natureza. Neste sentido, ainda carecemos da construção de projetos e programas interdisciplinares que nos façam avançar na compreensão do fenômeno informação. Nossas pesquisas avançam na direção de aproximações conceituais, às vezes também das escolhas quanto aos universos de investigação, o que é insuficiente para a construção da interdisciplinaridade, que ocupou um espaço caro nas discussões fundantes da Ciência da Informação. 
I\&S - Considerando que você é docente em cursos de graduação em Biblioteconomia e Arquivologia e na pós-graduação em Ciência da Informação, poderia nos falar sobre sua experiência com essas áreas na UFBA?

HFG - Minha experiência como docente e orientadora nos níveis da pós-graduação e graduação no Instituto de Ciência da Informação da Universidade Federal da Bahia sinaliza para a existência de avanços quanto a compreensão das especificidades e zonas possíveis de convergência e dialogia entre as disciplinas científicas da Arquivologia e Biblioteconomia, e destas com o campo científico da Ciência da Informação. Observo que os egressos dos cursos de graduação em Arquivologia e em Biblioteconomia, que ingressam na pós-graduação em Ciência da Informação, passam a compreender mais densamente os fundamentos de suas disciplinas, assim como a contribuição da Ciência da Informação no desenvolvimento da pesquisa acerca dos seus objetos de estudo e de atuação profissional. Algumas atividades desenvolvidas na pós-graduação buscam promover a integração entre os discentes da graduação e pós-graduação no interior dos grupos de pesquisa, na iniciação científica, assim como nos seminários de pesquisa da UFBA e do nosso Programa, congregando os discentes desses dois níveis de formação, alargado o olhar dos estudantes e docentes. Essas experiências têm motivado iniciativas marcantes dos nossos discentes das graduações em Arquivologia e Biblioteconomia, a exemplo da organização e realização do I Encontro Interdisciplinaridades: Arquivologia, Biblioteconomia e Museologia: estreitando relações. O centro e diretórios acadêmicos dos estudantes dos Cursos de Graduação em Biblioteconomia, Arquivologia e Museologia da UFBA se articularam e, em conjunto, realizaram este histórico evento, no qual se buscou discutir as zonas de especificidades de cada uma dessas disciplinas científicas, assim como suas zonas de convergências e promissoras de um diálogo potencializador da construção de projetos e programas interdisciplinares no campo da informação. Esta iniciativa emergente do nível da graduação parece representar um relevante alerta, o de que chegou o tempo de superarmos "os afastamentos" que nos enfraquecem, em direção ao projeto interdisciplinar sonhado pela Ciência da Informação.
I\&S - Poderia traçar uma linha histórica sobre a Ciência da Informação no Brasil: apontando o antes, o agora e as perspectivas futuras?

HFG - Por entender que o espaço destinado a respostas em uma entrevista seria limitado para traçarmos a história da Ciência da Informação, como também por compreender que essa história está fartamente relatada e analisada na literatura científica da área, me limito a expor uma reflexão que faço e que considero contributiva para a construção de uma auto-avaliação do nosso campo. Na minha compreensão os atores sociais e os agenciamentos realizados no processo de constituição e institucionalização do campo científico da Ciência da Informação atuaram no sentido da construção de uma ciência interdisciplinar, no entanto, os dados da realidade indicam que os esforços de pesquisa e institucionalização dos espaços institucionalizados de formação dos pesquisadores e de representatividade em sociedades científicas e agências de fomento tornaram mais evidente sua potência interdisciplinar. Por outro lado, tomando como referência o crescimento da pósgraduação na área, o fortalecimento da pesquisa e também do avanço quantitativo e qualitativo dos seus pesquisadores, observa-se possibilidades de avanço na construção de projetos e programas, tanto de uma formação alargada no plano das graduações, quanto em projetos e programas de formação de docentes e pesquisadores, que tomarão como ofício o fazer científico na área. Desses projetos e programas se formará o lastro necessário à cooperação e à disponibilidade para a atuação em complementaridade, o que tornará mais efetiva a interdisciplinaridade que, desde o seu nascimento, embalou o ideário do campo científico da Ciência da Informação.

I\&S - É possível pensar em uma Ciência da Informação geográfica e politicamente situada? P.ex., uma Ciência da Informação do Brasil, ou dos Estados Unidos, ou da América Latina.

HFG - Considero ser possível um pensamento Latino Americano na Ciência da Informação, o que não significa dizer necessariamente uma "outra" Ciência da Informação, isto é, uma Ciência da Informação Latino Americana. Entendo que a história, os princípios e fundamentos de uma ciência sempre estão pautados na busca do 
universal, no entanto, as diversas correntes de pensamento, agregam ao universal, concepções e perspectivas locais, situacionais, contextuais que, quando desenvolvidas e fortalecidas podem, a partir do debate e do consenso possível, vir a ser incorporadas aos princípios e fundamentos universais. Neste sentido, creio que as reflexões e experiências Latino Americanas no campo da Ciência da Informação têm contribuições importantes a dar, e que os pesquisadores latino americanos podem e devem estreitar parcerias, colaborações, para que projetos e programas de pesquisa em cooperação adensem e consolidem um pensamento Latino Americano da Ciência da Informação.

I\&S - Como você está vivendo a experiência de estar à frente da ANCIB?

HFG - Minha experiência como presidente da ANCIB muito me honra, pela confiança dos meus pares no nosso trabalho, no nosso compromisso com o desenvolvimento e fortalecimento do campo da Ciência da Informação. Desde o processo eleitoral até o momento atual, pude observar o fortalecimento do nosso campo e da nossa Associação, por meio da expansão quantitativa e qualitativa do conjunto de pesquisadores e pesquisas. Esse conjunto se expressa cientificamente e politicamente, o que sinaliza nosso avanço na construção de agenciamentos para a expansão do próprio processo de institucionalização da nossa Ciência no Brasil, passando pelo fortalecimento de nossas entidades representativas, como a ANCIB, com o estabelecimento de critérios e processos de escolha e mecanismos de apoio e ações articuladas com os nossos pares que assumem funções de representação da área junto às agências de fomento e avaliação.

Enquanto presidente da ANCIB posso afirmar ainda que nos sentimos muito motivados com a observação do crescimento da pós-graduação em Ciência da Informação no Brasil. Esse crescimento demonstra o avanço da competência instalada na área, o que vem promovendo mudanças muito relevantes em muitas frentes, chegando mesmo a resultar em uma repercussão positiva na formação e na pesquisa em nível das graduações da área. Essa repercussão é muito importante, no sentido de que as graduações da área são as instâncias que preparam os quadros que adentrarão na formação em nível da pós-graduação.
Dentro desse quadro, a nossa gestão vem mantendo contatos e um trabalho mais aproximado com nossos representantes de área, com a Compós, com a Abecin, Conarq, CFB, buscando sempre desenvolver ações articuladas que fortaleçam o campo. Ainda pensando nesse processo de qualidade na formação dos nossos pesquisadores do futuro, na última assembleia da ANCIB foi criado o Fórum de Discentes da ANCIB, no qual os sócios estudantes terão a possibilidade de estabelecer suas pautas, seus debates e suas proposições. Ouvi-los e integrá-los na construção da ANCIB, criando seu espaço de expressão e atuação, representa a afirmação de uma perspectiva do fortalecimento da formação dos quadros científicos da área, não apenas como pesquisadores de excelência, mas especialmente como pesquisadores orgânicos de excelência.

Numa outra perspectiva, destaco que a ANCIB deve atuar em muitas frentes para fortalecer a Ciência da Informação no Brasil, como no desenvolvimento de um trabalho de articulação com outras associações científicas e redes internacionais de pesquisa, assim como empreender esforços em uma atuação mais sistemática junto aos órgãos governamentais definidores das políticas públicas de implantação de novos cursos de pós-graduação, de avaliação dos cursos, dos periódicos, livros e eventos da área, como também responsáveis pelo fomento à pesquisa. No entanto, todas as ações, incluindo estas, demandam a adequação da estrutura da ANCIB, com a plena resolução de problemas de caráter administrativo e contábil, como a regularização da sua situação fiscal e financeira, com adequações de seus instrumentos e dispositivos reguladores da sua gestão. Desde que tomamos posse, estamos atuando de modo concentrado e firme para alcançarmos a solução dessas questões, sem abandonar a promoção e condução das discussões de caráter científico e político, que representam a essência e a razão de ser da nossa Associação.

Por fim, eu diria ainda que dirigir uma associação científica nos coloca frente ao desafio, de certo modo comum a todos os pesquisadores do campo, de seguir perseguindo o estabelecimento das condições de excelência na formação de docentes e pesquisadores e na produção do conhecimento científico da área, cientes de que a consolidação do campo impõe uma visão orgânica e comprometida com o coletivo, o que exige qualidade também na atuação política de consolidação dos nossos fóruns e entidades representativas. 